Article

\title{
Projecting More Sustainable Product and Service Designs
}

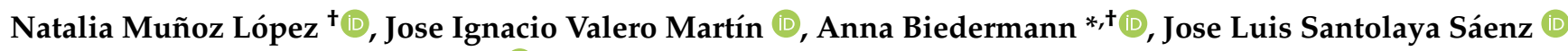 \\ and Aranzazu Fernández-Vazquez (D)
}

Design and Manufacturing Engineering Department, EINA, University of Zaragoza, 50018 Zaragoza, Spain; nataliam@unizar.es (N.M.L.); ivalero@unizar.es (J.I.V.M.); jlsanto@unizar.es (J.L.S.S.); aranfern@telefonica.net (A.F.-V.)

* Correspondence: anna@unizar.es

+ Member of the OAAEP research group, financed by the Government of Aragon with FEDER funds.

Citation: Muñoz López, N.;

Valero Martín, J.I.; Biedermann, A.; Santolaya Sáenz, J.L.;

Fernández-Vazquez, A. Projecting

More Sustainable Product and Service

Designs. Sustainability 2021, 13, 11872.

https: / / doi.org/10.3390/

su132111872

Received: 3 September 2021

Accepted: 21 October 2021

Published: 27 October 2021

Publisher's Note: MDPI stays neutral with regard to jurisdictional claims in published maps and institutional affiliations.

Copyright: (c) 2021 by the authors. Licensee MDPI, Basel, Switzerland. This article is an open access article distributed under the terms and conditions of the Creative Commons Attribution (CC BY) license (https:/ / creativecommons.org/licenses/by/ $4.0 /)$.

\begin{abstract}
Product and service development based on sustainable criteria is one of the poles of innovation in design activity. Public policies, consumer preferences, and corporate social responsibility lead to the growing importance of applying sustainability principles in the current design process. However, to make this practice widespread, sustainability assessment must be included in the curricula of bachelor's and master's degrees in design, so that the graduates have the precise tools to use when they start their professional careers. Furthermore, sustainable design methods have mainly been applied to improve only the environmental behavior of products. In this work, a methodology that simultaneously evaluates environmental, economic, and social aspects was applied to project more sustainable designs of products and services. This approach was implemented in higher education to develop Bachelor's and Master's degree final projects by design engineering students. Collaboration with different companies and institutions allowed the study of a number of cases. The production process of a cash management machine, the service provided by a public nursery school, and the development of an itinerary exhibition were addressed. In each case, product and service requirements were analyzed, sustainability indicators were obtained, and more sustainable designs could be proposed. This experience is also part of a global strategy at the University of Zaragoza to support the implementation of the UN's Sustainable Development Goals, enhancing sustainability education. The intention of this paper is to present a methodology for more sustainable design, and examples of its application that other teachers can easily follow when teaching design of products or services.
\end{abstract}

Keywords: sustainable design; product and service design; sustainability strategies; design engineering students

\section{Introduction}

Today, designers face the challenge of reaching the best possible combination of both operative and sustainable aspects in the design of products and services. Thus, design engineering students need to learn and apply new methods and techniques for addressing issues such as evaluating the sustainability of a system and integrating sustainability strategies in the design activity.

Sustainable design was initially focused on reducing the environmental impacts of industrial products [1]. At the same time, a life cycle perspective, which takes into account the whole process from the raw material generation from natural resources to the product final disposal, was included in the development of eco-design methods [2,3]. Thus, a number of factors in the manufacturing, assembly, maintenance, and end-of-life stages of the product life cycle are incorporated at the very beginning of its design process. The eco-design methodology is assisted by a set of techniques, rules, and tools [4,5]. Two types of tools are required: tools to evaluate environmental impacts, and tools to achieve environmental improvements. One of the most important tools to measure environmental 
impacts is the Life Cycle Assessment (LCA) method [6,7]. Meanwhile, to identify potential improvement actions, one of the most remarkable tools is the Life Cycle Design Strategy Wheel (LiDS-W) [8], which proposes the application of a wide number of eco-design rules throughout the entire product life cycle. Andriankaja et al. [9] compiled, in a summarized manner, different eco-design tools used by researchers to achieve the assessment and improvement of environmental impacts. Numerous studies have focused on applying eco-design to a comprehensive range of products. In the case of service design, criteria such as user experiences and expectations are emphasized [10].

The eco-design methodology is mainly approached from a technical perspective, with limited attention to the human-related aspects. Nevertheless, applying a sustainable approach means not only taking into account environmental impacts, but also introducing socio-ethical principles and models that are economically feasible. Three dimensionslooking simultaneously at economic aspects (profit), environmental issues (planet), and social concerns (people)—should be considered [11,12]. In order to evaluate sustainability in this triple bottom line, a new perspective is being introduced through the Life Cycle Sustainability Assessment (LCSA) framework [13-15]. Applying this approach, different impact categories are evaluated in the environmental dimension; economic aspects are usually valued by considering costs, and social issues are analyzed by establishing different stakeholders' groups. These groups (workers, local community, society, consumers, and value chain actors) are recognized according to the UNEP guidelines [16]. Each sustainability dimension is measured by a set of indicators according to different works [17-19]. Since social issues are not easy to quantify, semi-quantitative and qualitative information is also usually proposed. After the separate assessment of each dimension, a global improvement in the sustainability of the product or service can be obtained. If improvements are not achieved in all dimensions, the global improvement will depend on the criteria applied to weigh each of the dimensions [20].

Sustainability integration in product and service development has been the objective of numerous researchers. Maxwell and Van der Vorst [21] proposed using a checklist of the most usual environmental and socioeconomic impacts at each stage of the life cycle. Maxwell et al. [22] elaborated "The Guide for Developing Sustainable Products and Services in Industry", which collates some of the most significant sustainable product and service development endeavors until that moment. On the other hand, Gagnon et al. [23] indicated that sustainability tools should be used in conjunction with existing approaches associated with state-of-the-art design practice. In addition, Pesonen and Horn [24] recommend the use of tools to expedite the assessment process and communicate the results easily to key decision makers. With the objective of introducing the design process toward sustainable system solutions, Ceschin [25] proposed the implementation of socio-technical experiments, while Vezzoli et al., [26] suggested the application of design criteria and guidelines to stimulate the generation of ideas, as well as the use of comparative checklists and radar diagrams to visualize the results of the analysis. The design criteria applied in order to achieve more sustainable products and services must guarantee that the initial specifications of the designed product or service are still met $[27,28]$.

Ceschin and Gaziulusoy [29] carried out a comprehensive study on the response of the design discipline to sustainability issues; these authors cite diverse approaches that are increasingly focused on both the integrated combination of products and services and promoting new socio-technical systems in which not only technological advances, but also social and organizational innovations, are developed. Other authors also point out that designers have an opportunity to influence the development of socially responsible products [30], that design can influence the more sustainable behavior of the users [31], and that sustainability can be one of the factors that influence the positive perception of the product or service ahead of purchase [32].

Nevertheless, practical methods to value sustainability aspects in a triple dimension (specifically including social issues) have only recently been applied. In addition, studies regarding the sustainability performance of service systems and complex systems composed 
of products and services are rather limited [33,34]; hence, practical methods to address their sustainable design, (including a set of sustainability strategies) are scarcely developed [35]. Additionally, there is a need to implement research achievements in teaching programs in higher education.

Although $80 \%$ of the environmental impact of a product is estimated to be determined at the design stage [36,37], the introduction of sustainability assessment methods into the teaching practice in bachelor's and master's degrees in industrial design is still not widespread. For example, from 93 contributions to the 23rd International Conference on Engineering and Product Design Education held at VIA University in Herning, Denmark. 9-10 September 2021, only 7 of the contributions mentioned sustainability in the keywords, and just one presented by the authors focused on sustainability assessment with quantitative data [38]. Authors such as Østergaard, Leube and Walcher, and Sumter et al. [39-42] demonstrate the need for changes in the curricula of design degrees in order to develop sustainable competencies.

The aim of this work is to effectively achieve more sustainable products and services via the implementation of an approach in which sustainability improvements are evaluated according to the three pillars of sustainability: environmental, economic, and social impacts. This approach was formulated and put into practice by a group of professors at the University of Zaragoza who decided to include the sustainability issue in the development of final projects in bachelor's and master's degrees in industrial design and product development engineering. The methodology applied and results achieved in three different case studies, which include very different systems, are shown in the following sections.

This paper represents a practical example of how to introduce the sustainability assessment in teaching programs independently of the design topic addressed in the course. The aim of the methodology presented is to equip students with tools for the implementation of improvement strategies in their design, based on the sustainability criteria.

\section{Methods}

Regardless of the product or service design methodology that is followed in design education, it certainly includes a phase of idea generation, concept development, and selection of the most appropriate proposal for the detailed design. In the proposal selection stage, there is the potential not only to include the sustainability criteria in the decisionmaking process, but also to improve the chosen proposal by applying the sustainability strategies, and assessing the different design options in the environmental, economic, and social dimensions. This procedure gives the designers the option to look deeper into the design that they deliver, and to be conscious of the impacts it provokes.

The sustainability improvement of products and services is addressed by applying both the LCSA approach and engineering design methods, via the systematic development of three phases (Figure 1): (1) sustainability assessment of the initial product/service; (2) product/service redesign, taking into account initial specifications and sustainability criteria, and the consequent sustainability assessment of the redesign; and (3) comparison of sustainability results between initial design and redesign, to detect whether enhancements have been achieved.

Phase 1: Sustainability Assessment

In Phase 1, the initial product/service is analyzed, and the LCSA methodology is applied to assess its sustainability. Four steps are carried out: First, the goal and scope of the study are established, and the functional unit is also settled. Next, inventory data are obtained, and product/service performance is characterized by a set of metrics. Then, the environmental, economic, and social dimensions are assessed using a number of appropriate indicators. Finally, results are analyzed, determining the most significant impact factors. The elementary flows exchanged within the system boundaries include inputs (raw materials, energy consumption, consumables, money inputs, etc.) and outputs (products, waste and production energy costs, salaries, payments, etc.). Depending on 
the depth and the scope of the research, the entire life cycle or specific stages along the product/service life cycle can be analyzed.

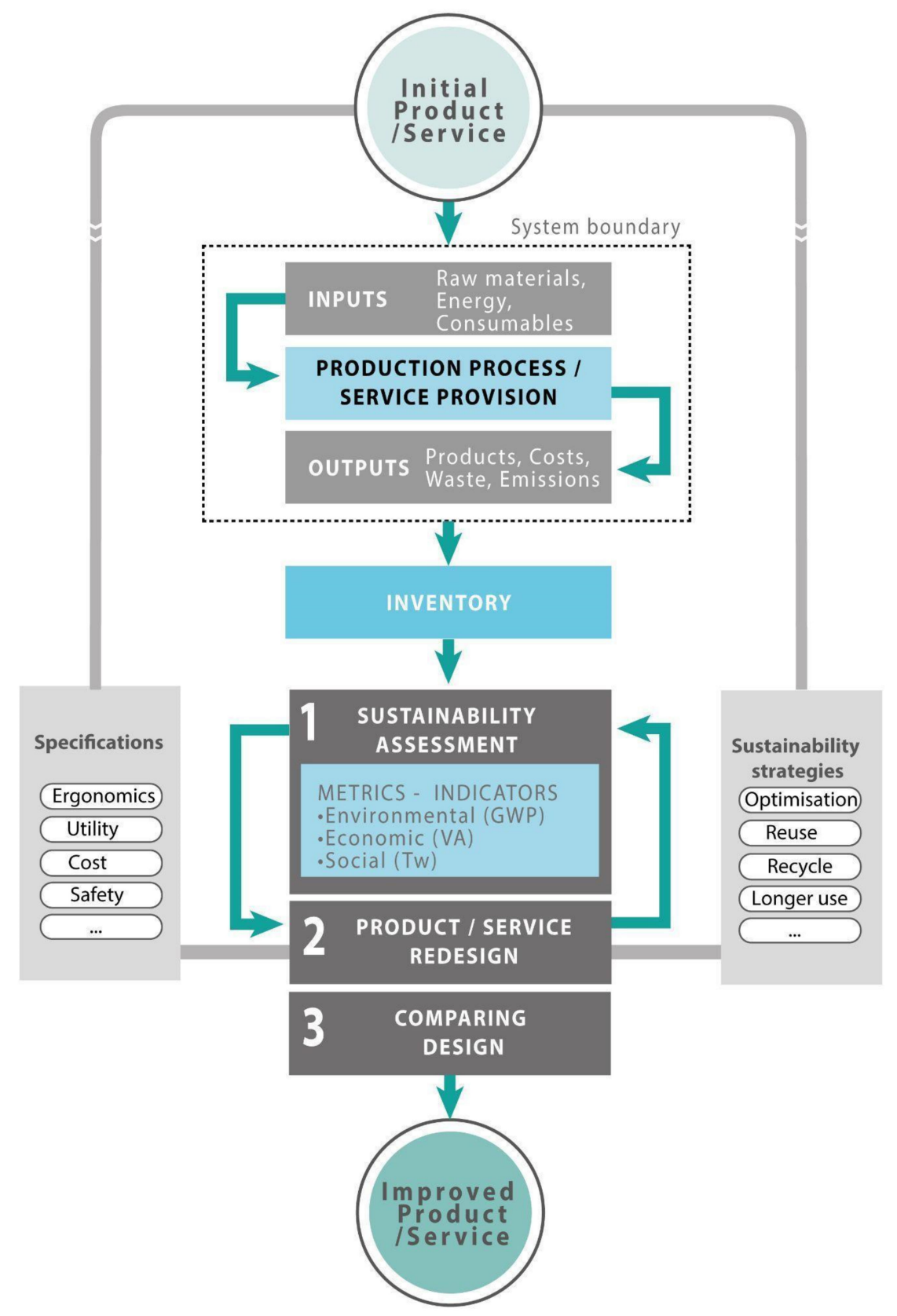

Figure 1. Sustainable design methodological scheme (by authors).

\section{Phase 2: Sustainable Redesign}

The definition of new design concepts or the transformation of existing ones is usually carried out when those improvements or innovations detected are included in the initial design. Nevertheless, the specifications of the product or service must be met. In the same way, these specifications should not be compromised if sustainability strategies are applied. The selection of low-impact materials, reduction in material usage, and lower energy consumptions are usual strategies to environmentally improve products. If the socioeconomic approach is also taken into account, the relevant stakeholders should be identified, and strategies to improve specific requirements and social indicators should be applied.

Phase 3: Comparing Designs 
A new sustainability assessment is undertaken for the redesigned product/service. The resulting indicators are compared with those obtained for the initial design, with the aim of detecting whether sustainability improvements have been achieved. A global improvement in the system sustainability will be obtained if improvements in the three dimensional indicators are achieved. However, if this is not the case, the improvement in the system sustainability will depend on criteria to evaluate each dimension. These criteria can vary widely in each product/service evaluated, in accordance with the concerns and choices of the stakeholders and decision makers. Hence, different weighting factors can be applied to sustainability indicators to express the relative importance of each one of the sustainability dimensions. Three main methods for weighting indicators can be used: equal weighting, statistics-based weighting, and expert-opinion-based weighting [20].

In this work, the design of more sustainable product/service is backed by the evaluation of a set of metrics and indicators. Metrics provide designers with useful information on the system performance, and are indispensable to later obtain sustainability indicators. The selection of metrics depends on both the product/service characteristics and the score of the study. Thus, very different metrics can be used in each study case. Metrics considered useful to measure a product manufacturing process are the mass of raw materials, the amount of material removed, and the units of the product manufactured within a period of time, as well as the energy consumption and different production costs. In the case of service provision, metrics should compute the consumption and costs of different resources used throughout the service operation, but also the number of users or customers that make use of the service over a period of time.

In addition, sustainability indicators that can be quantitatively evaluated were selected. The global warming potential $\left(\mathrm{GWP}_{100}\right)$, used in all research papers in which environmental impacts are assessed, was the indicator selected to measure the environmental dimension. The ProBas database (https:/ / www.probas.umweltbundesamt.de/php/index) [43] php (accessed on 13 April 2017) was used to obtain environmental indicators of different materials and products, and emission factors of electric commercial companies [44] were applied to evaluate greenhouse gas emissions from both electric and fuel consumption. The value added (VA), or net operating profit, was selected for the economic dimension, since it is a useful indicator to show the economic feasibility of any activity.

Finally, the workers were selected as the main category of stakeholders, and the social dimension of sustainability was valued by quantifiable indicators. Qualitative or semiquantitative information of social sustainability were obtained in various studies due to the social aspects being difficult to quantify. However, the use of quantifiable indicators is proposed in those works in which the ability to improve the sustainability of a system is a main objective of study $[19,35]$. The metrics and sustainability indicators used in this work are defined in Table 1.

Table 1. Metrics and sustainability indicators.

\begin{tabular}{|c|c|}
\hline \multicolumn{2}{|r|}{ Metrics Used in Product Manufacturing } \\
\hline $\mathrm{Mp}(\mathrm{Kg})$ & $\begin{array}{c}\text { Product Mass is obtained by the difference between the mass of raw materials and the masses of both material } \\
\text { removed and byproducts generated in the production process. }\end{array}$ \\
\hline $\mathrm{Wp}(\%)$ & $\begin{array}{l}\text { Waste expresses the efficient use of raw materials in the production process; it is obtained by the mass ratio of } \\
\text { the material removed and the raw materials required in the production. }\end{array}$ \\
\hline Epr $(\mathrm{kW} \cdot \mathrm{h})$ & $\begin{array}{c}\text { Energy Consumption is obtained by the sum of consumption in each operation carried out throughout the } \\
\text { product manufacturing process. }\end{array}$ \\
\hline Cpr (EUR) & $\begin{array}{c}\text { Production Costs refers to the costs associated with the manufacturing process, and includes the following } \\
\text { groups: raw materials, labor, consumables, and indirect costs. }\end{array}$ \\
\hline Tpr (h) & Production Time expresses the average time to develop a productive operation. \\
\hline $\operatorname{Pr}$ (units/year) & $\begin{array}{l}\text { Production represents the units of product manufactured within a time period. Average production is obtained } \\
\text { from the times involved in each productive operation. }\end{array}$ \\
\hline \multicolumn{2}{|r|}{ Metrics Used in Service Operation } \\
\hline Us & \multirow{2}{*}{$\begin{array}{l}\text { Service Users expresses the number of users or customers that make use of the service over a period of time. } \\
\text { Service Workers is the number of workers that are involved in the service provision. Different categories of } \\
\text { emplovees can be established. }\end{array}$} \\
\hline Ws & \\
\hline
\end{tabular}


Table 1. Cont.

\begin{tabular}{|c|c|}
\hline \multicolumn{2}{|r|}{ Metrics Used in Service Operation } \\
\hline Es $(\mathrm{kW} \cdot \mathrm{h})$ & $\begin{array}{c}\text { Energy Consumption is obtained by the sum of different forms of consumption (electric, gas, etc.) throughout } \\
\text { the service development. }\end{array}$ \\
\hline $\operatorname{Cs}(€)$ & $\begin{array}{l}\text { Service Costs refers to the service operation costs, and includes the following main cost groups: energy, labor, } \\
\text { consumables, and indirect (insurance, taxes, etc.). }\end{array}$ \\
\hline Fs (EUR) & $\begin{array}{l}\text { Service Fee represents the revenues obtained by the service provider from fees paid by users/customers who } \\
\text { make use of the service. }\end{array}$ \\
\hline \multicolumn{2}{|r|}{ Sustainability Indicators } \\
\hline $\begin{array}{c}\mathrm{GWP}_{100} \\
\left(\mathrm{KgCO}_{2} \mathrm{eq}\right)\end{array}$ & $\begin{array}{l}\text { Global Warming Potential represents the total emissions of greenhouse gases, calculating the radiative forcing } \\
\text { over a time horizon of } 100 \text { years. }\end{array}$ \\
\hline VA (EUR) & $\begin{array}{l}\text { Value Added expresses the net operating profit; it is a useful indicator to present the economic feasibility of } \\
\text { any activity. }\end{array}$ \\
\hline Tw (h) (workers) & Working time represents the average time required by the workers to develop an activity. \\
\hline Us/Ws (workers) & $\begin{array}{c}\text { Ratio between numbers of users and workers represents the average number of users that each worker has } \\
\text { to attend. }\end{array}$ \\
\hline To (h) (users) & Service operating time represents the period of time in which the service is developed. \\
\hline
\end{tabular}

\section{Case Studies}

In this section, different cases that include the design of products and services are addressed. In each case, a more sustainable product/service is projected, taking into account that only some stages of its life cycle are analyzed. First, a cash management machine (product) is studied, and an improved design to obtain a more sustainable production process is presented. Next, the performance of a public infant school (service) is reviewed, and various improvements are projected. Finally, sustainability-oriented changes in the system used to exhibit contents (product) are proposed in the development of an itinerary exhibition (service). Projects were carried out by students individually, and were tutored or co-tutored by chosen professors over the course of approximately 6 months, in weekly sessions. The case studies were chosen by both student and teacher, and were approved by the degree academic commission that checks whether the object and scope of the work are adequate. Each project corresponds to 12 ECTS credits.

\subsection{Case 1: Cash Management Machine}

The design of this machine is characterized by two elementary functions: counterfeit detection, and money accounting and safe storage. It consists of four different modules, which are shown in Figure 2. Money notes are placed in the feeding module, where they are sequentially rolled on to the detection module, and then to the safe deposit box, through the transportation module. The closing module acts as general cover for the machine (except for the safe box). Rejected banknotes from the detection module are driven out from the machine.

Inventory data in the manufacturing stage were obtained from a detailed study of the production process and specific data provided by the company. This process is schematically shown in Figure 3. The raw materials required in the manufacture of the mechanism and structural parts are mainly steel (AISI 430, AISI 303, and ST 37-2) and aluminum alloy ( $\mathrm{Al} \mathrm{6061),} \mathrm{which} \mathrm{are} \mathrm{mainly} \mathrm{received} \mathrm{in} \mathrm{the} \mathrm{industrial} \mathrm{facility} \mathrm{as} \mathrm{sheets}$ and bars. A wide number of components are manufactured by external companies, and are incorporated into the production process along with the final assembly process. The manufacture of this product includes cutting, folding, and machining, as well as welding operations, component assembly, and testing of the product. Times required for operation, energy consumption and money flows are shown in Figure 3. All data are expressed per functional unit (one machine). 


\section{Closing module}

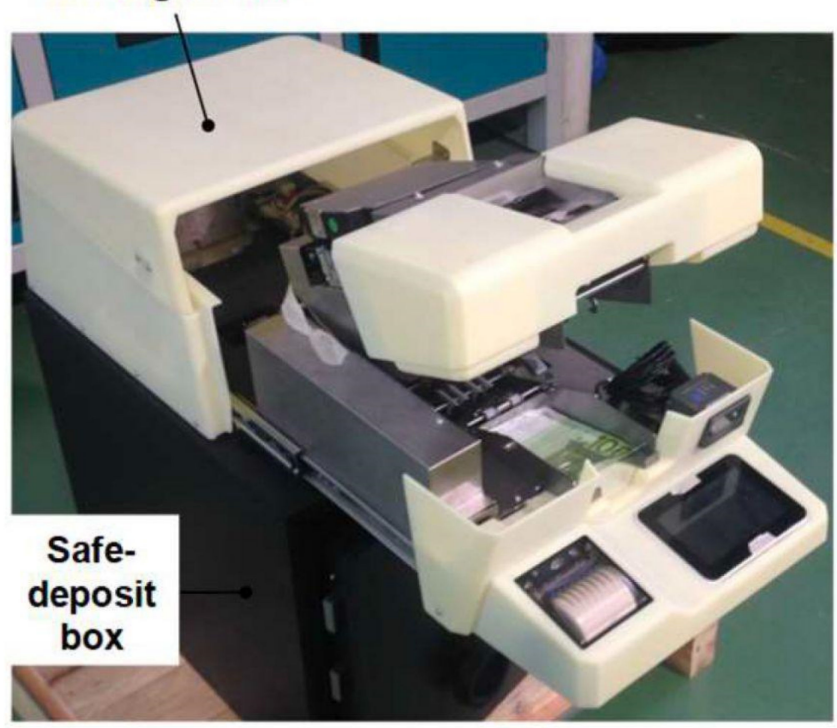

Specifications:

Vstorage: 100 bills $/ \mathrm{min}$; Vtransport: $1.2 \mathrm{~m} / \mathrm{s}$

Accept/reject function; Secure smart safe

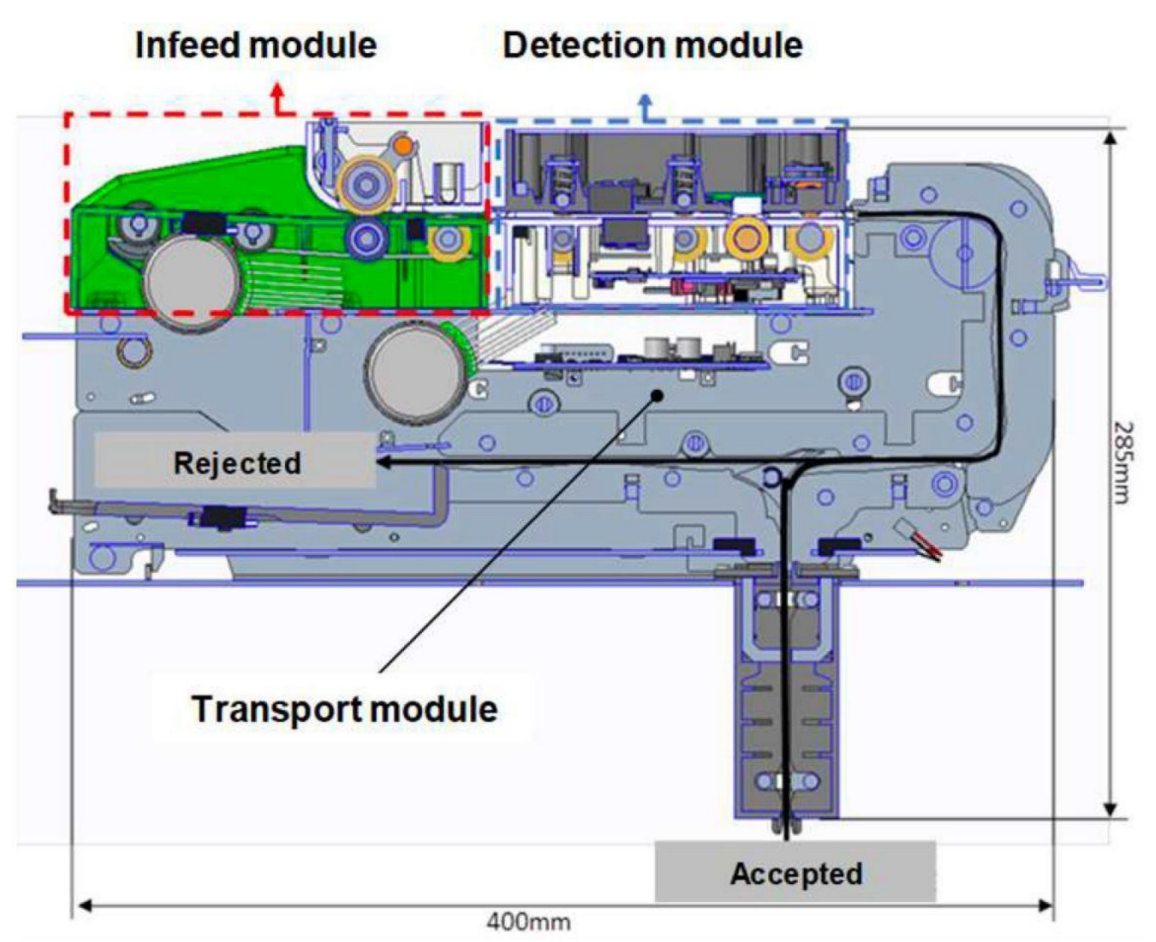

Figure 2. Case 1: cash machine scheme (by authors). 


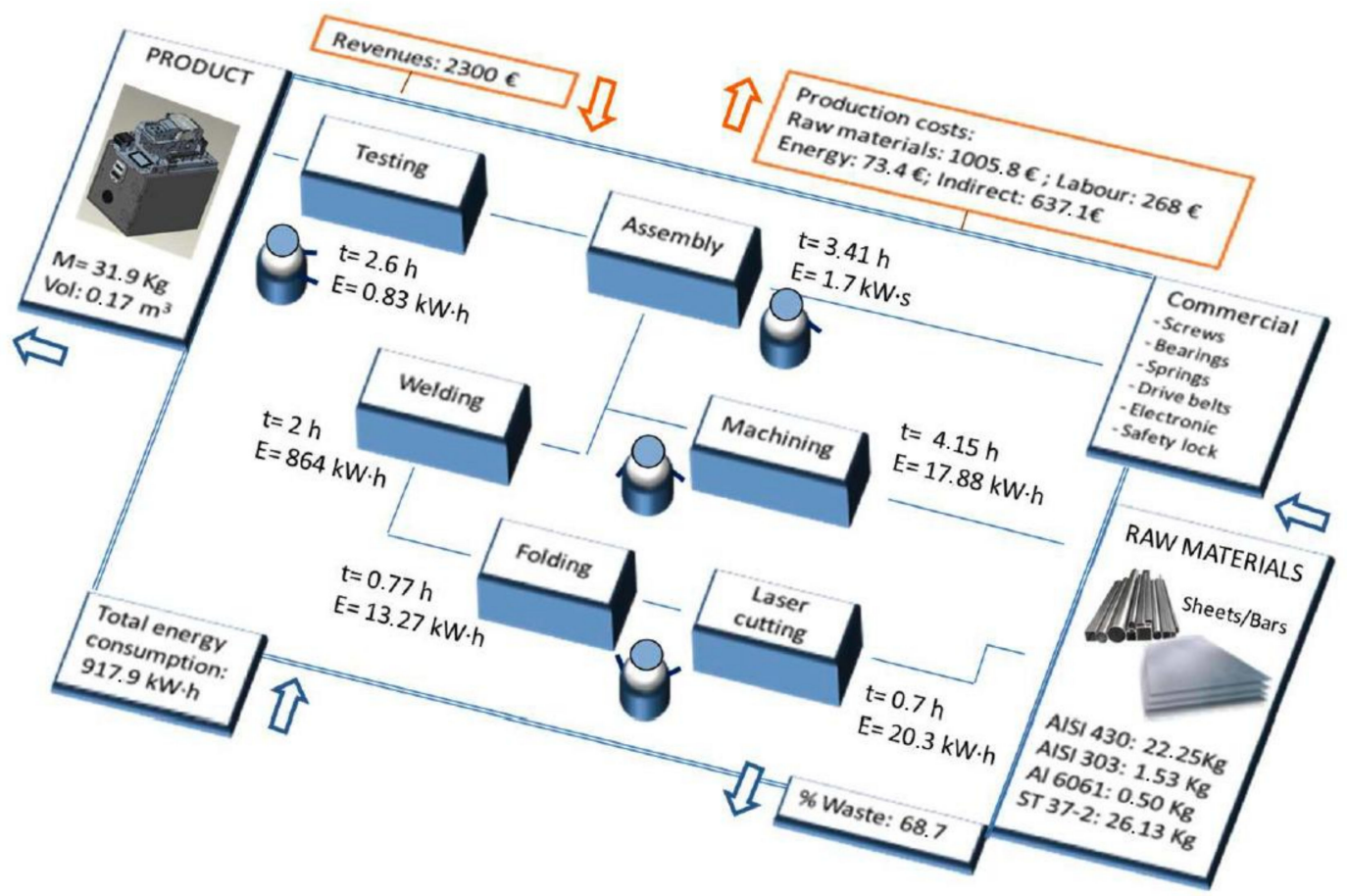

Figure 3. Case 1: scheme of the production process. Metrics of the initial design (by authors).

Welding of the safe box parts is the operation with the highest energy consumption, and machining of the components involved in the transport module is the operation for which the most time is required. The total mass of the raw materials is $50.4 \mathrm{~kg}$. It can be observed that an elevated residue proportion is produced (68.7\%). The energy consumption for the whole manufacturing process is $917.9 \mathrm{~kW} \supsetneq \mathrm{h}$. Production costs-including materials, labor, energy, and indirect costs-are EUR 1911.3. Raw materials account for $\sim 52 \%$ of the total cost. Regarding times required for operations, it can be observed that the machining time is the highest $(4.15 \mathrm{~h})$. Production is $\sim 2000$ units per year. A summary of the metrics evaluated in the initial production process can be found in Table 2, where they can be comparatively analyzed with those obtained later from the application of sustainability strategies in the product design.

Table 2. Case 1: application of sustainability strategies.

\begin{tabular}{cccccc}
\hline & Strategies & & Tpr (h) & Epr (kW·h) & Cpr (EUR) \\
\hline $\begin{array}{c}\text { (Str1) Material change } \\
\text { in rollers }\end{array}$ & Al 6061(machining) & 0.54 & 2.17 & 22.8 \\
\cline { 3 - 7 } $\begin{array}{c}\text { (Str2) Alternative } \\
\text { production technique }\end{array}$ & POM (injection mold) & 0.25 & 1.26 & 6.3 \\
\hline $\begin{array}{c}\text { (Str3) Reuse } \\
\text { of the safe box }\end{array}$ & Production by folding & 0.03 & 13.26 & 12.41 \\
\hline
\end{tabular}

In addition, sustainability indicators were evaluated. As shown in Table 4, a total of $146.8 \mathrm{Kg} \mathrm{CO}_{2}$-eq are emitted, due to both utilization of raw materials and power consumption in the production of each machine. According to revenues obtained from sales, the net operating profit of the company is EUR 388.7. In the social dimension, the workers category is selected. The average working time required to manufacture one unit is $13.04 \mathrm{~h}$. 
Next, three different strategies named Str1, Str2, and Str3 were applied as more sustainable design options for this product:

- Str1: The material used in the rollers of the transportation module was changed from aluminum to POM (polyoxymethylene);

- Str2: The design of some of the components used in both the in-feed and transport modules was partially changed in order to be manufactured by die stamping instead of folding;

- Str3: The reuse of the safe box from machines that are no longer used was studied in the production of the new machines.

These strategies are proposed taking into account that initial product specifications (storage capacity, note processing speed, and detection level) should be not modified. Changes in particular metrics of the production process due to the implementation of these strategies are summarized in Table 2. When POM is selected in the production of rollers (Str1), machining operations in aluminum are avoided, involving a reduced costs and an energy consumption decrease of $42 \%$. If the design of specific components is modified to be manufactured by stamping instead of by the folding technique (Str2), it also shows an improvement in terms of cost (21\%) and energy consumption (6\%). Moreover, when reusing safe box (Str3) material, cost and energy consumption are cut down to their minima. Note that this alternative only includes additional operations to guarantee the assembly of the safe box from one to another.

In addition, global metrics are calculated for the cash machine production applying each sustainability strategy; the results are summarized in Table 3. When Str1 is applied, slight reductions in the product mass, energy consumption, and cost metrics are observed. Production time decreases by around 7\%, so production could be improved. If Str2 is applied, very small reductions in energy consumption and manufacturing costs are also obtained. Finally, when Str3 is considered, very notable reductions in raw materials, energy consumption, and production costs are observed due to the welding operation being considerably simplified. Nevertheless, the initial cost (materials, energy, etc.) from the first time that the safe box was manufactured should be divided and considered.

Table 3. Case 1: metrics comparison.

\begin{tabular}{ccccccc}
\hline & Mp (Kg) & $\begin{array}{c}\text { Epr } \\
\mathbf{( k W \cdot h )}\end{array}$ & $\begin{array}{c}\mathbf{C}_{\mathbf{R M}} \\
\mathbf{( E U R )}\end{array}$ & $\begin{array}{c}\text { Cpr } \\
\text { (EUR) }\end{array}$ & Tpr (h) & $\begin{array}{c}\text { Pr } \\
\text { (Us/Year) }\end{array}$ \\
\hline $\begin{array}{c}\text { Initial product } \\
\text { (Str1) Material change }\end{array}$ & 31.97 & 915.48 & 301.09 & 1911.3 & 4.15 & 2000 \\
$\quad \begin{array}{c}\text { in rollers } \\
\text { (Str2) Alternative }\end{array}$ & 31.90 & 914.32 & 284.55 & 1874.8 & 3.86 & 2110 \\
$\begin{array}{c}\text { production tech. } \\
\text { (Str3) Reuse of the }\end{array}$ & 31.97 & 914.04 & 295.12 & 1904.1 & 4.15 & 2000 \\
$\begin{array}{c}\text { safe box } \\
\text { Final product }\end{array}$ & 31.97 & 56.71 & 111.09 & 1071.3 & 3.96 & 2738 \\
$\quad$ Str1+Str2+Str3) & 31.90 & 39.88 & 105.12 & 1027.7 & 3.61 & 2848 \\
\hline
\end{tabular}

Sustainability indicators were calculated from rough data to enable a better understanding and comparison between the initial product and the redesigned one. As shown in Table 4, significant improvements were achieved in the environmental, economic, and social dimensions when all sustainability strategies were simultaneously applied. 
Table 4. Case 1: sustainability indicators.

\begin{tabular}{cccc}
\hline & $\mathbf{G W P}_{\mathbf{1 0 0}} \mathbf{~} \mathbf{K g C O}_{\mathbf{2}}$-eq) & VA (EUR) & $\mathbf{T}_{\mathbf{W}} \mathbf{( h )}$ \\
\hline Initial product & 146.8 & 388.7 & 13.04 \\
(Str1) Material change in rollers & 146.6 & 425.2 & 11.28 \\
(Str2) Alternative production technique & 133.5 & 395.9 & 11.57 \\
(Str3) Reuse of the safe box & 107.5 & 1228.7 & 9.38 \\
Final product (Str1+ Str2+Str3) & 94.2 & 1272.3 & 9.02 \\
\hline
\end{tabular}

If Str1 is applied, significant improvements are achieved in both economic and social indicators; meanwhile, the $\mathrm{GWP}_{100}$ indicator barely changes. In the case of Str2 application, $\mathrm{GWP}_{100}$ reduces by approximately $9 \%$, VA increases by $1.8 \%$, and Tw reduces by $3.6 \%$. On the other hand, Str3 is the sustainability strategy that causes the most substantial improvement in all indicators-particularly in the environmental and economic dimensions. It was assumed that the revenues and workforce of the manufacturing company were not modified.

The resulting values for each sustainability indicator are comparatively shown in Figure 4.

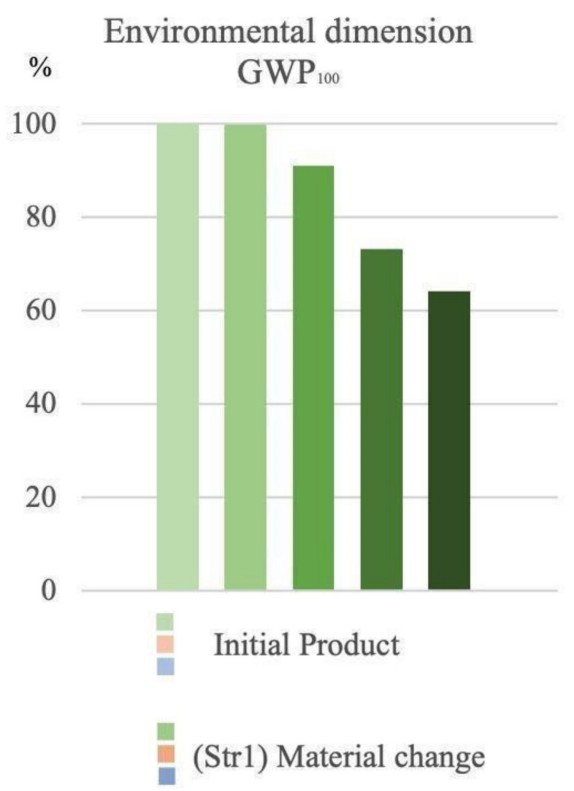

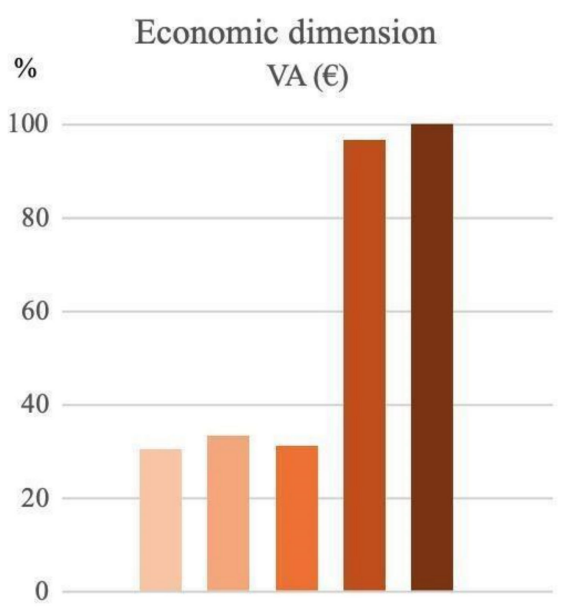

0

(Str2) Alternative production technique

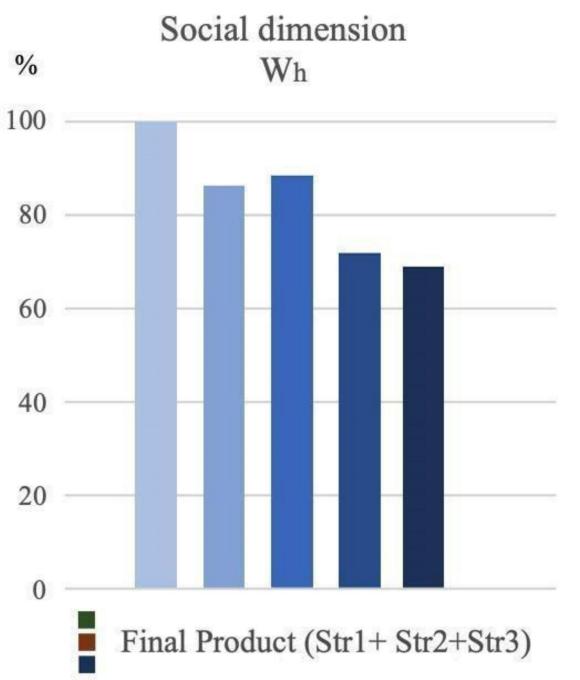

(Str3) Reuse of components

Figure 4. Case 1: comparison of sustainability indicators (by authors).

The effects of each strategy are clearly exposed. Since positive results were obtained, a more sustainable product could be developed. In view of these results, Str1 and Str2 are currently being implemented by the manufacturing company, and Str3 is under study. The reuse of the safe box is a very promising strategy, although its implementation is complex. Recycling processes are increasing in efficiency with regard to recovered products, but a better tracking of those products leaving the factory should be also implemented to facilitate the recovery process.

\subsection{Case 2: Daycare Service}

The service provided by a public infant school is considered in this case. The educational center is located in a rural region of Spain with a low population density (around $9 \mathrm{hab} / \mathrm{Km}^{2}$ ), and receives children from 4 months to 3 years of age, who live in the village itself and in other small localities within a radius of $20 \mathrm{~km}$.

The nursery school is open from Monday to Friday, from 8:45 a.m. to 1:15 p.m. in the morning, and from 2:15 p.m. to 5:30 p.m. in the afternoon. Users can request entry 
either for full-time hours or for the morning only. The service development takes place in a two-floor edifice with six classrooms that are used depending on the needs of each course As is shown in Figure 5, the construction has a circular cross-section. Based on the ratios of children per school unit or classroom [45], the city council estimates the needs of the next course and determines the number of classrooms that will be put into operation. Four classrooms are currently in use; the first floor houses the C1 and C2 classrooms, and the ground floor houses the $\mathrm{C} 3$ and $\mathrm{C} 4$ classrooms. The number of children, their age range, and the surface of each classroom with its pertinent bathroom surface are shown in Figure 5. The $\mathrm{C} 1$ classroom is filled to capacity at all service operation times; $\mathrm{C} 2$ and $\mathrm{C} 3$ are used only part-time, and C4 is dedicated to caring for 6 babies up to one year old in the morning, and for 12 children from 0 to 2 years old in the afternoon.

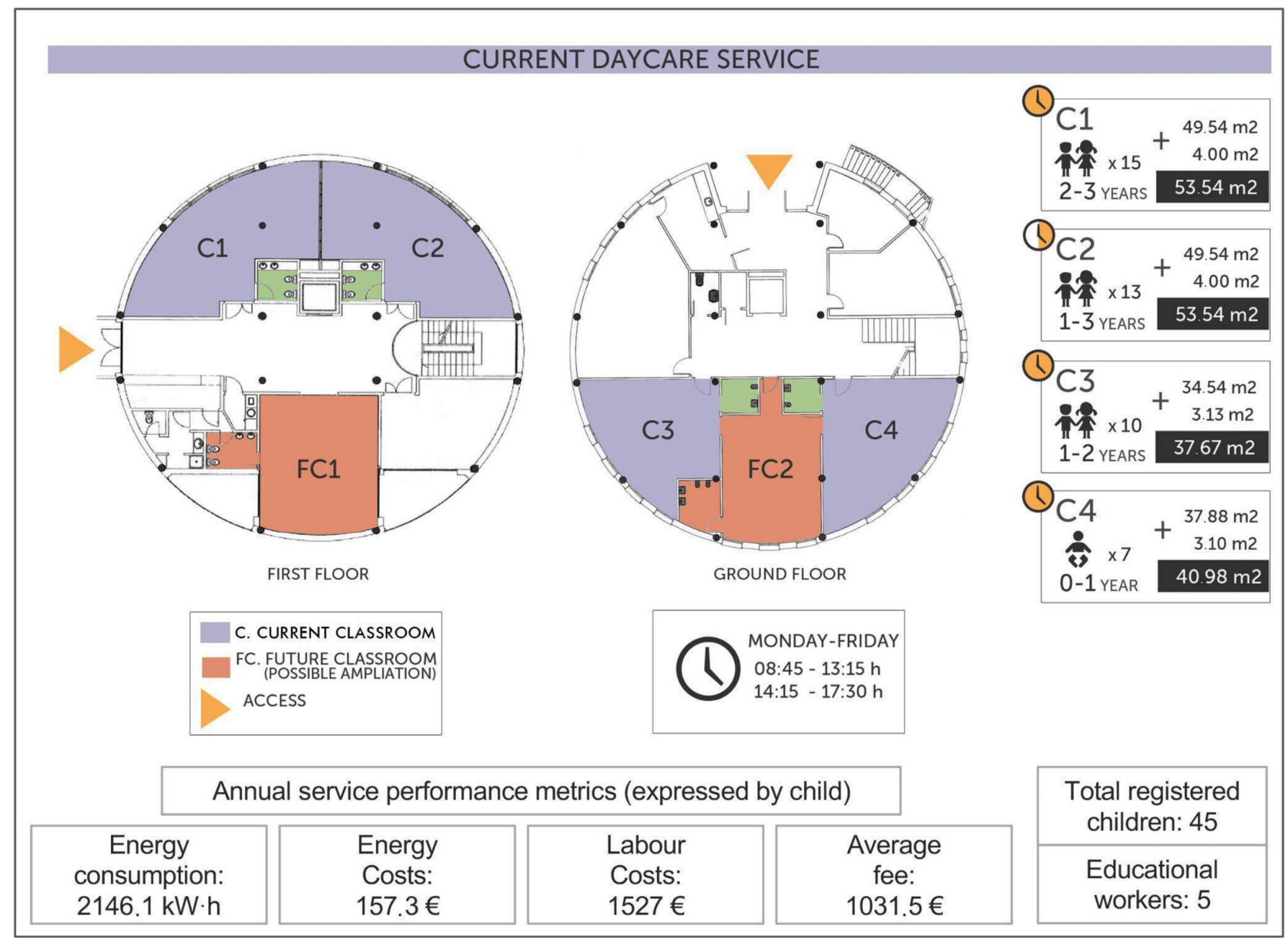

Figure 5. Case 2: initial daycare service: distribution of children and classrooms, and operational metrics (based on [46]).

It should be noted that, currently, the infant school is open from Monday to Friday, for $7 \mathrm{~h}$ and $45 \mathrm{~min}$ each day (with $1 \mathrm{~h}$ closed at noon). The annual performance of the infant school involves an electricity and gas consumption of 9967 and $96,607 \mathrm{~kW} \supsetneq \mathrm{h}$, respectively, and the total energy cost is EUR 7078/year. Data were obtained thanks to the collaboration of municipal institutions and the workers of the nursery school. A total of five educational workers (two working $37.5 \mathrm{~h} /$ week and three working $22.5 \mathrm{~h} /$ week) take care of the different groups of children. Total labor costs are EUR 68,713/year. On the other hand, the payment of user fees is made monthly. In addition, a single initial payment of EUR 80 corresponding to the registration is made. The monthly fee for a full-time user is EUR 95, while the monthly fee for a morning-only user is EUR 75. Likewise, reduced fees or 
bonuses are applied according to the particular conditions of each family, based on salary income and number of children.

Metrics obtained for the initial service development are recapped in Figure 5. It should be noted that a total of 45 children are registered. A minimum surface of $2.9 \mathrm{~m}^{2} /$ child is calculated for the $\mathrm{C} 1$ classroom. Average energy consumption per child is $2146.1 \mathrm{~kW} \cdot \mathrm{h}$, and costs due to energy and labor are EUR 157.3 and 1527, respectively. Table 5 summarizes the sustainability indicators of the initial service, which are calculated using the practical information provided by service operation metrics, along with those gathered later from the redesign service. In the environmental dimension, emissions of $585.3 \mathrm{Kg}$ of $\mathrm{CO}_{2}$-eq per child are produced (this calculation is based on the energy consumption). To obtain the VA economic indicator, monetary inputs and operation costs were calculated. The children's fee (EUR 1031.5/child) is one the most important inputs in the infant school, and is a relatively low cost because the service is supported by a high public finance. Thus, an annual VA of EUR 249.2/child is obtained (a 20.1\% increase in the effectiveness of the public subvention is obtained). Finally, two indicators-the maximum number of children per caregiver, and the operating time of the daycare service-were selected to quantify social aspects, since social demands will be the focus of the service improvement strategies exposed below.

Table 5. Case 2: sustainability indicators.

\begin{tabular}{ccccc}
\hline & $\begin{array}{c}\mathbf{G W P}_{\mathbf{1 0 0}} \\
\left.\mathbf{K g C O}_{\mathbf{2}} \mathbf{e q}\right)\end{array}$ & $\begin{array}{c}\text { VA } \\
\text { (EUR) }\end{array}$ & $\mathbf{T}_{\mathbf{s}} \mathbf{( h )}$ & $\begin{array}{c}\text { Max } \\
\text { Children/Caregiver }\end{array}$ \\
\hline Initial daycare service & 585.3 & 249.2 & 7.75 & 18 \\
Projected daycare service & 577 & 143.9 & 9 & 15 \\
\hline
\end{tabular}

The demands of different stakeholders were taken into account to project sustainability strategies in the service provision. On the one hand, parents' requests were focused on the service hours; they expressed special interest in keeping the nursery school open at noon, allowing for a longer and more flexible schedule that was compatible with their working routines. On the other hand, the main requirement of educational workers was to reduce the number of children per caregiver, as they consider the current ratio to be too high.

Thus, a new schedule from 8:00 a.m. to 5:00 p.m. was proposed from Monday to Friday, representing an increase of $1 \mathrm{~h}$ and $15 \mathrm{~min}$ per day. According to the preferences expressed by the parents, the enrollment was expected to increase by 8 children; as a result, it was necessary to increase the number of available classrooms, and to allow the flexible entry and exit of children within certain time slots. Additional resources should be used to implement these changes: a new classroom should be used, and a new educational worker should be hired. Inventory data of the service projected and subsequent assessment of sustainability indicators were carried out. Use of classrooms and distribution of children are shown in Figure 6. A maximum number of 15 children per classroom (for the $\mathrm{C} 1$ classroom) can be now estimated due to the flexible schedules and the new worker introduced. Thus, a minimum surface of $3.5 \mathrm{~m}^{2} /$ per child can be obtained. Moreover, the occupation of other classrooms is slightly modified. Normative requirements are fulfilled (20 children/class and $2 \mathrm{~m}^{2}$ /child in the case of children from 2 to 3 years old). 


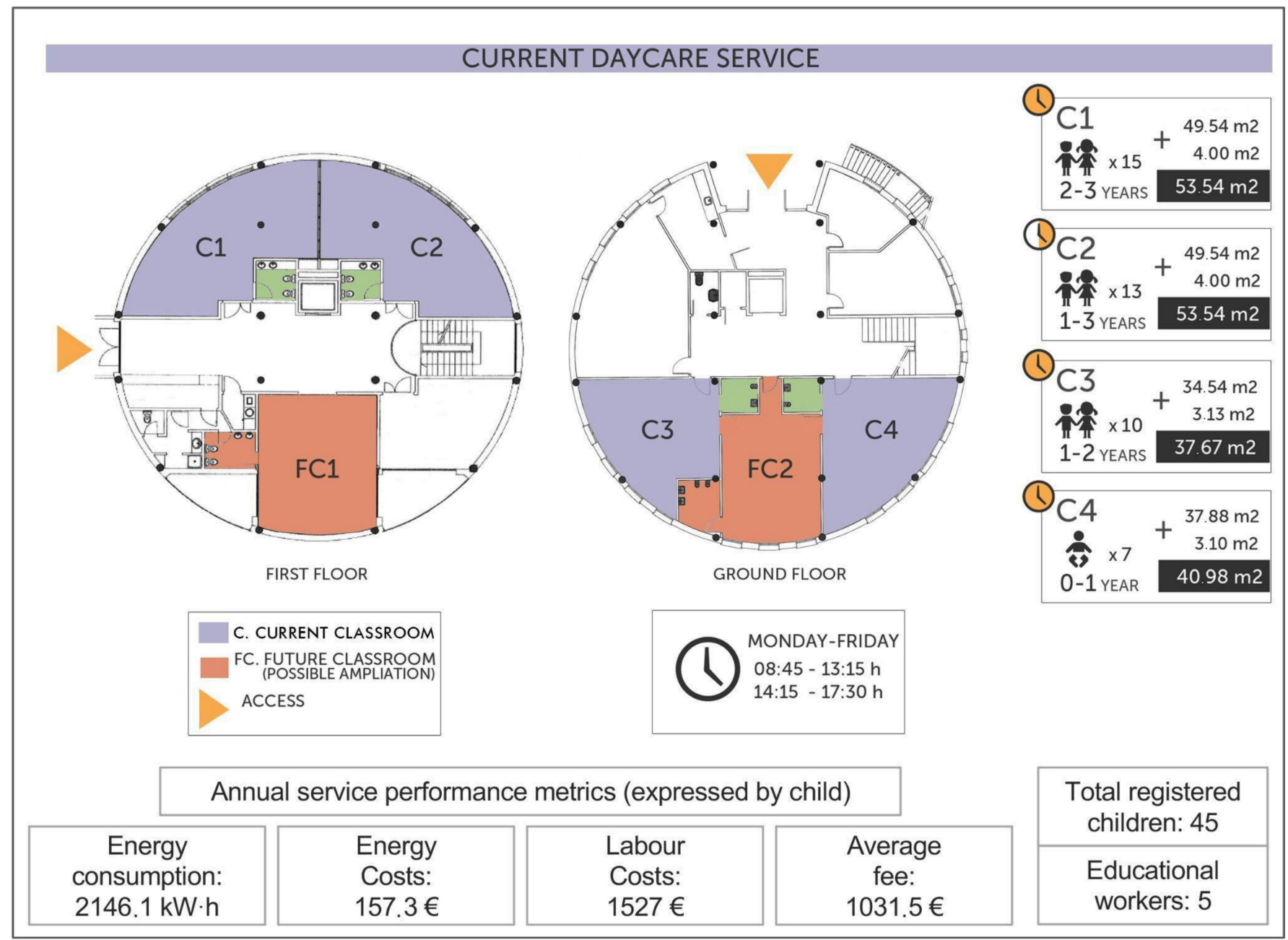

Figure 6. Case 2: projected daycare service: distribution of children and classrooms, and operational metrics (based on [46]).

The new adjustment in the service's opening hours increases the energy consumption and operation costs of the nursery school. Taking into account that 53 children could be registered, average energy consumption per child is $2111 \mathrm{~kW} \supsetneq \mathrm{h}$ in the new service design, and energy costs are EUR 154.7/child. The labor costs increase in the new service design (EUR 1685.8/child), since one more educational worker is required. Thus, a slight reduction of $1.5 \%$ in energy consumption per child is estimated, although the redesigned daycare service increases the opening hours. Meanwhile, a notable increase in labor costs $(10.4 \%)$ is obtained.

Environmental, economic, and social indicators for the projected service are recapped in Table 5. Greenhouse gas emissions of $577 \mathrm{Kg}$ of $\mathrm{CO}_{2}$-eq per child are obtained. A value added of EUR 143.9/child is calculated, taking into account that the average fee per child is unchanged. Total financial inputs due to the children's fees and public financial support are increased due to the increase in the number of children registered, but operational costs are also increased due to operating time being amplified and another worker being required. In the social dimension, the children/caregiver ratio is 15 (indicator associated with the educational workers' demands) and the operating time of the daycare service is $9 \mathrm{~h}$ (indicator associated with parents' requirements).

The comparison of the results obtained in the initial and redesigned service is presented in Figure 7. 

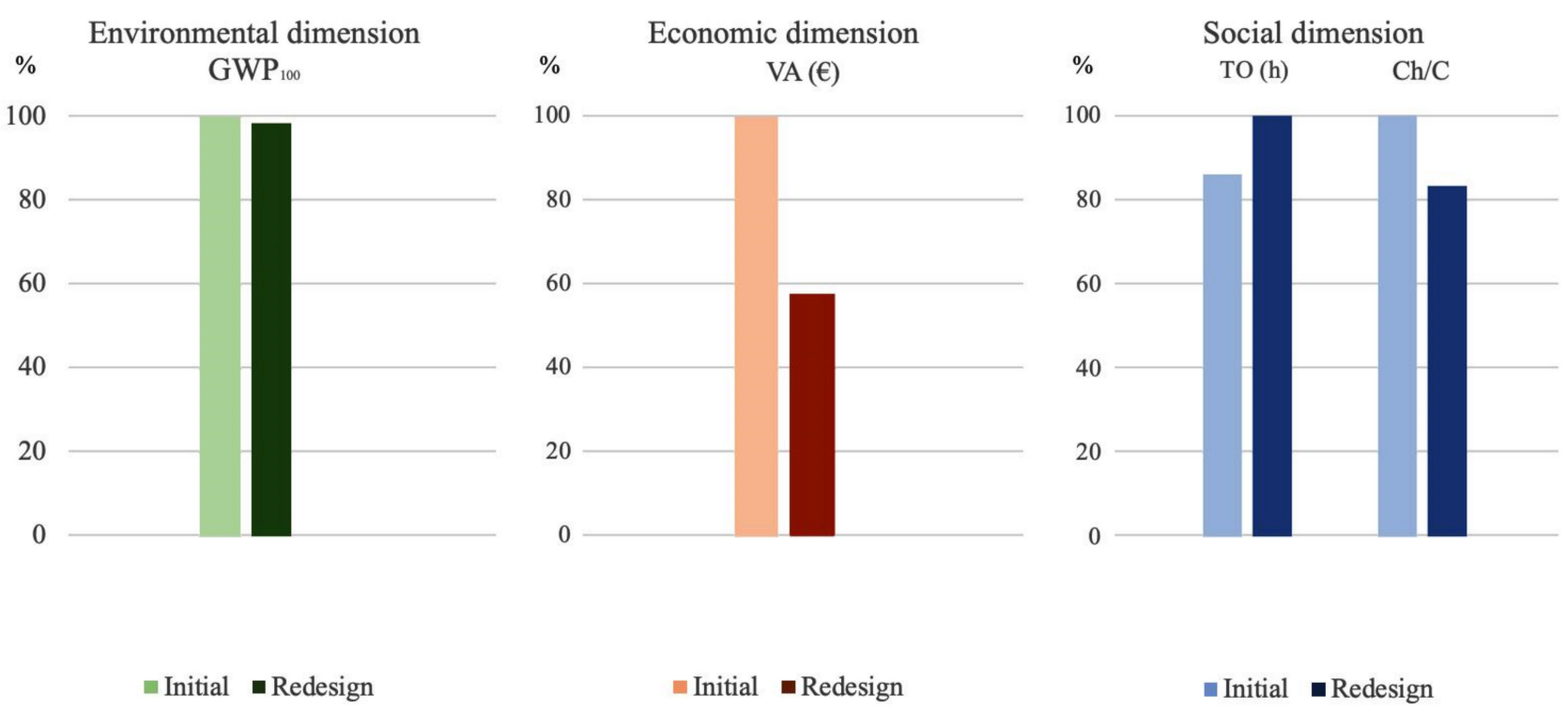

- Initial $\quad$ Redesign

- Initial - Redesign

- Initial — Redesign

Figure 7. Daycare service: sustainability indicators comparison (by authors).

The results show a slight reduction in the environmental impact and considerable improvements in the social indicators. Furthermore, these positive results affect the economic dimension, in which a significant decrease in the VA indicator is calculated.

\subsection{Case 3: Itinerant Exhibition}

In this case study, a cultural service, which consists of an itinerant exhibition dedicated to the painter Francisco de Goya, is reviewed. In particular, the elements used in the suitable conditioning of a total area of approximately $300 \mathrm{~m}^{2}$ to didactically transmit the painter' legacy are analyzed. The exhibition will travel to 11 different Spanish and Portuguese destinations (Zaragoza, Bilbao, Valladolid, Santiago, Oporto, Lisbon, Sevilla, Málaga, Murcia, and Valencia) after its inauguration in Madrid, staying for 3 months in each location. Inventory was carried out using primary data collected during the creation and operation stages of the itinerant exhibition in the first destination. The conditioning works of the exhibition area involve the construction of a system of modular walls with the printed material exposed on them (printed and cut-out vinyl). A total of 37 modules of $1 \times 3 \times 0.2 \mathrm{~m}$ each are conveniently distributed in the exhibition hall (Figure 8 ) and attached to the walls with struts and brackets. The structure of each module is made up of wooden slats, joined by dowels and adhesives, and later covered with medium-density fiberboard (MDF) panels. Later, successive products are applied to them (filler, primer, and two layers of paint). Finally, printed vinyl and cut-out vinyl are set on these modules. When each exhibition finishes, the modular walls system can be disassembled and reused in the next destination. However, printed materials must be manufactured again in each destination, because it is not possible to reuse them. A summary of the materials used and activities carried out in the current design of the exhibition hall is shown in Figure 8.

It should be noted that the mass of raw materials used along the entire tour of the exhibition is up to $4178 \mathrm{~kg}$, which implies a fuel consumption of more than $1000 \mathrm{lin}$ the transport of materials between those destinations in which the exhibition will be open. Total costs due to the conditioning works of the exhibition area-including manufacturing, transport, and assembly of the modular walls system in the exhibition hall—are EUR 55,722. 


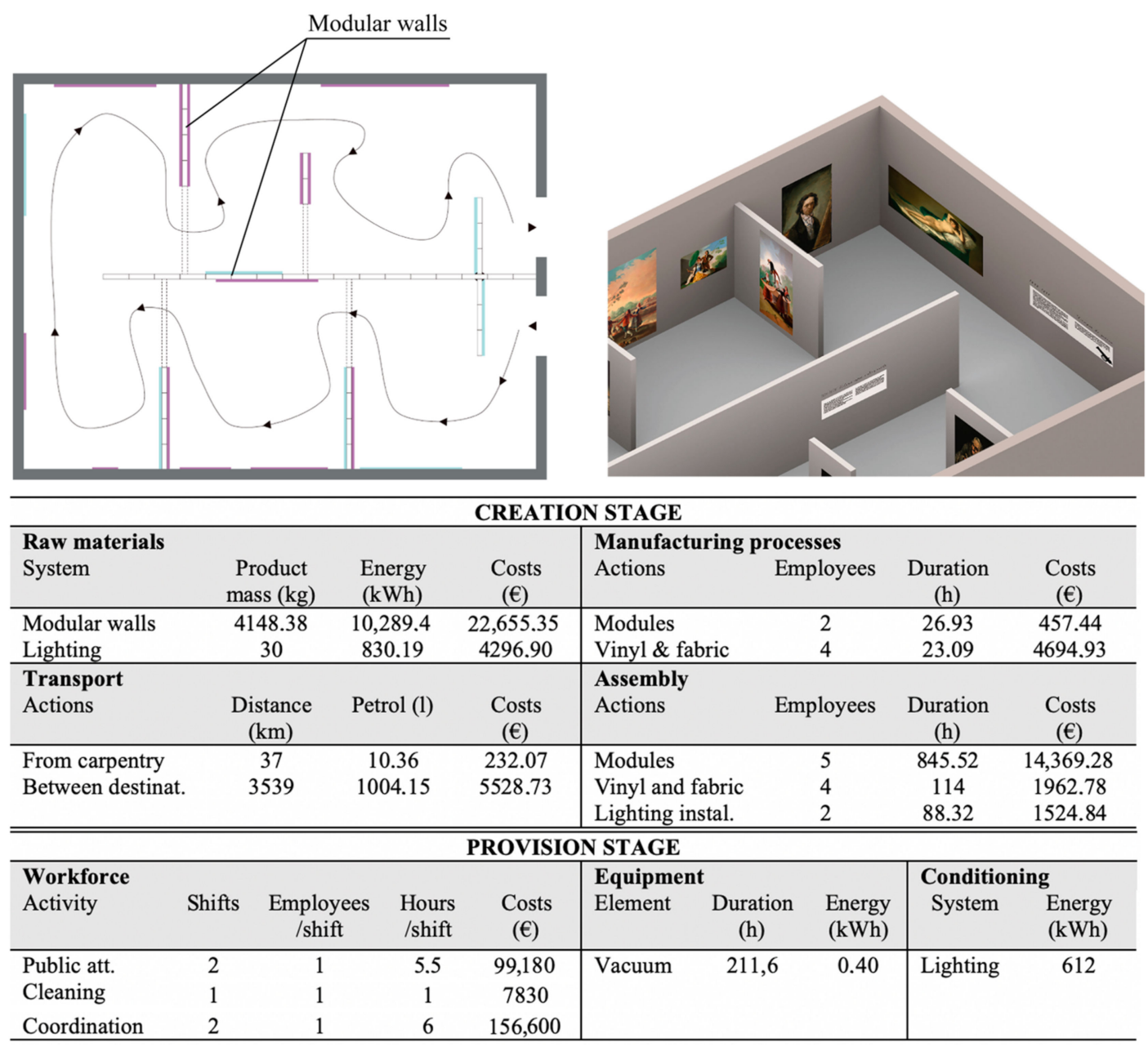

Figure 8. Case 3: itinerant exhibition: inventory data of the initial design (by authors).

Data associated with the operation stage are also briefly exposed in Figure 8. The exhibition was open every day (except on Monday) for $11 \mathrm{~h}$ over the course of 3 months. Activities of public attention and coordination were carried out in two shifts of 5.5 and $6 \mathrm{~h}$, respectively, each day (one worker in each shift). Meanwhile, cleaning activities were performed in one shift of $1 \mathrm{~h}$. In each destination, a total of five workers were required during the exhibition performance; total labor costs were EUR 263,610. The main energy consumption computed was due to lighting. On the other hand, revenues obtained from ticket sales were EUR 648,831. A total of 9011 visits were notched in the first destination, and the average price of the tickets was EUR 6. Sustainability indicators resulting from the itinerant exhibition's development are shown in Table 6; these are expressed per visitor, and two different stages are distinguished: creation of the exhibition space, and provision of the cultural service. As in the previous case studies, the sustainability indicators obtained in the initial design can be also compared with those calculated after applying sustainability strategies. Greenhouse gas emissions of $0.47 \mathrm{Kg}_{\text {of }} \mathrm{CO}_{2}$-eq were calculated, the net operating profit of the company was EUR 2.9, and the average working time was $0.22 \mathrm{~h}$. It should be noted that a negative VA was obtained in the creation stage. 
Table 6. Case 3: sustainability indicators.

\begin{tabular}{|c|c|c|c|c|c|c|}
\hline & \multicolumn{2}{|c|}{$\mathrm{GWP}_{100}(\mathrm{KgCO} 2-\mathrm{eq})$} & \multicolumn{2}{|c|}{ VA $(€)$} & \multicolumn{2}{|c|}{$T_{w}(h)$} \\
\hline $\begin{array}{l}\text { Exhibition with } \\
\text { walls system }\end{array}$ & \multicolumn{2}{|c|}{0.47} & \multicolumn{2}{|c|}{2.9} & \multicolumn{2}{|c|}{0.22} \\
\hline $\begin{array}{l}\text { Exhibition with } \\
\text { audiovisual system }\end{array}$ & \multicolumn{2}{|c|}{0.43} & \multicolumn{2}{|c|}{3} & \multicolumn{2}{|c|}{0.211} \\
\hline & Creation & Provision & Creation & Provision & Creation & Provision \\
\hline $\begin{array}{l}\text { Exhibition with } \\
\text { walls system }\end{array}$ & 0.13 & 0.34 & -0.5 & 3.4 & 0.015 & 0.205 \\
\hline $\begin{array}{l}\text { Exhibition with } \\
\text { audiovisual system }\end{array}$ & 0.01 & 0.42 & -0.3 & 3.3 & 0.006 & 0.205 \\
\hline
\end{tabular}

In order to reduce the impact caused by the construction, transport, assembly, and painting activities of the modular walls system, which is currently used in the preliminary conditioning of the exhibition area, some changes to the exhibition methods were proposed. Strategies to improve the sustainability of the product/service should not compromise its initial specifications. Particularly, assembly/disassembly activities should be easily carried out in each destination. From the operational point of view, it is necessary to ensure appropriate attention to visitors. Thus, the use of an audiovisual system composed of 10 projectors, 8 speakers, and a computer is proposed to replace the current system of modular walls (Figure 9).

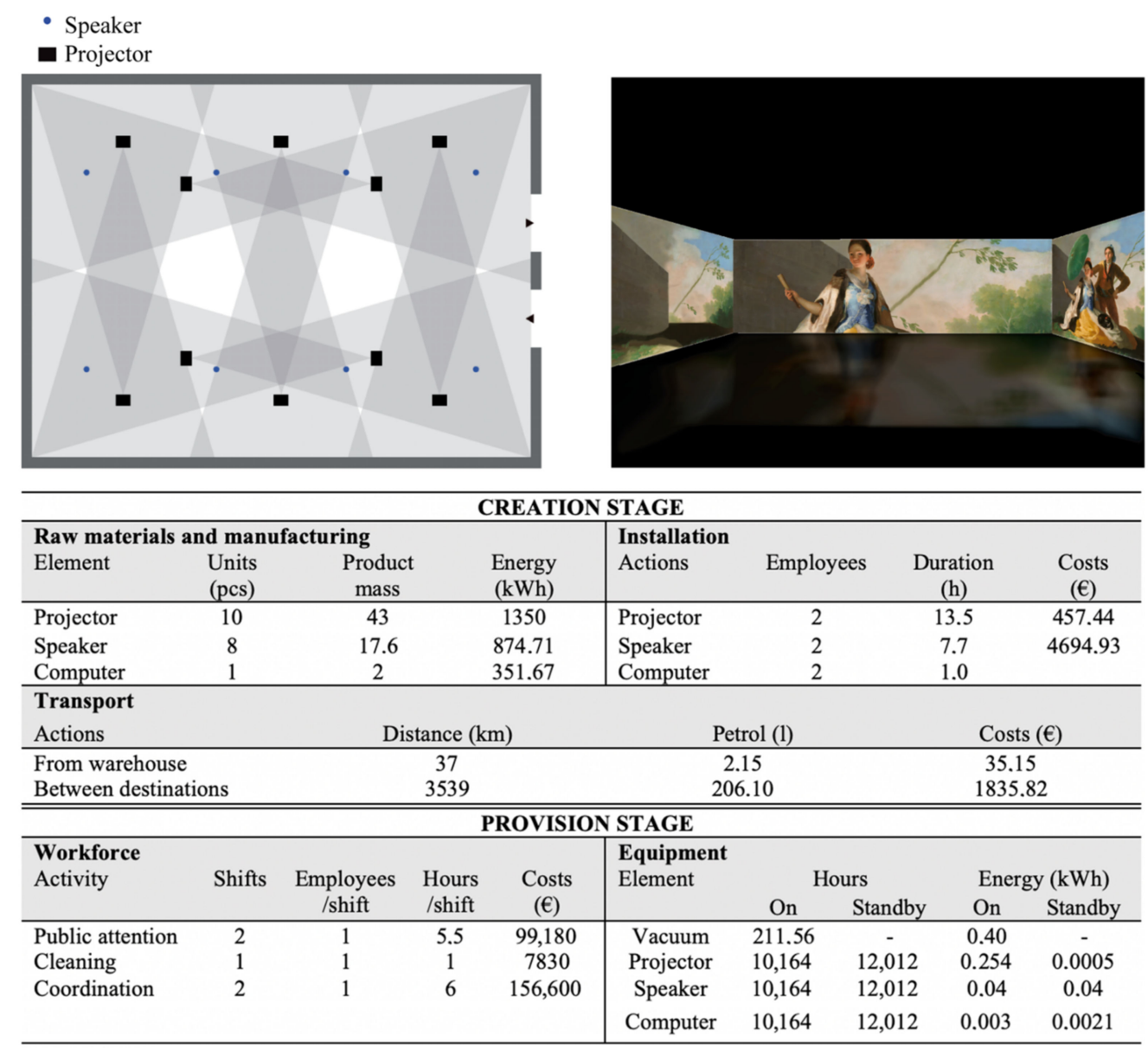

Figure 9. Case 3: itinerant exhibition: inventory data in the redesign (by authors). 
According to this strategy, a new inventory was obtained from the elementary flows exchanged throughout the system development. A summary of the inventory data can be consulted in Figure 9. The mass of raw materials is considerably reduced. In addition, assembly activities consist mainly of the installation, testing, and tuning of equipment. Thus, the energy consumption in the transport of materials between destinations reduces by $79 \%$, and the working times in assembly activities decrease by $61.3 \%$. Nevertheless, energy consumption during the operation stage increases by $10.6 \%$ due to the use of new electronic devices.

Sustainability indicators of the new exhibition design were also calculated. As is shown in Table 6, emissions of $0.43 \mathrm{Kg}$ of $\mathrm{CO}_{2}$-eq were obtained for the $\mathrm{GWP}_{100}$ indicator, a final VA of EUR 3 was calculated in the development of the exhibition with the audiovisual system, and $0.21 \mathrm{~h}$ was estimated for the Tw indicator.

Percentage variation of sustainability indicators can be analyzed in Figure 10.
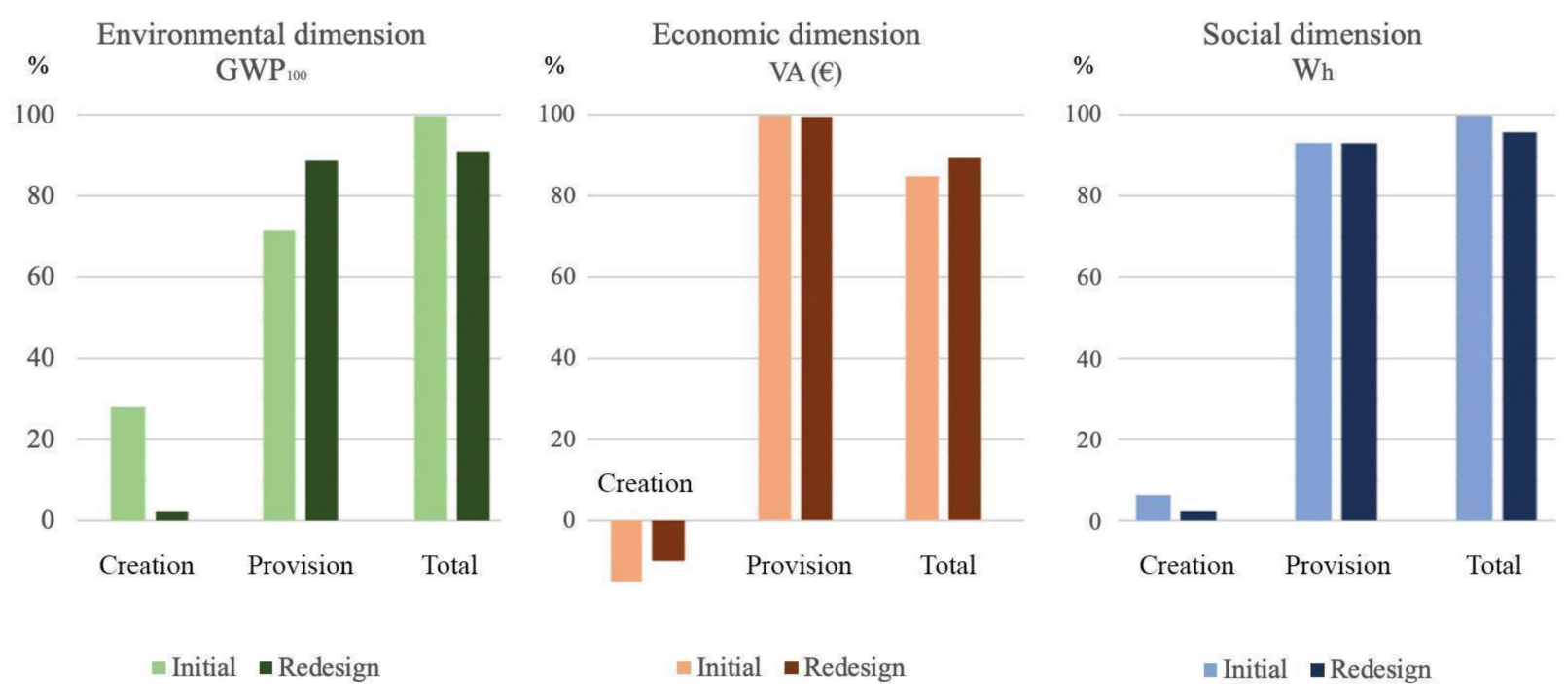

Figure 10. Case 3: sustainability indicators comparison (by authors).

If the global values are compared, we observe that $\mathrm{GWP}_{100}$ reduces by $8.6 \%$, VA increases by $5.5 \%$, and $\mathrm{Tw}$ reduces by $4 \%$. If the indicators of the different stages are compared, we observe that $\mathrm{GWP}_{100}$ increases in the provision stage, but considerably reduces in the creation stage due to the lesser quantity of materials being used. VA reduces in the provision stage, but the costs of the creation stage are also lower. Finally, Tw is not modified in the provision stage, but a significant improvement is obtained in the creation stage. The exhibition based on the audiovisual system generates improvements in the environmental and social dimensions. In order to determine whether a global sustainability improvement is achieved, criteria to define the weight coefficients assigned to each sustainability dimension should be applied.

\section{Conclusions}

This work presents a methodology for the development of more sustainable design of products and services, as well as practical examples of the implementation of this methodology in the academic context of the bachelor's and master's degree final projects.

The methodology is based on the quantitative assessment and improvement of specific sustainability indicators, and is structured in three main phases: (1) sustainability assessment of the initial product/service design; (2) application of strategies to improve sustainability of the initial product/service; and (3) sustainability evaluation of the new design, and comparison of results obtained for both designs. A number of functional metrics are used to obtain specific data on the product/service that is the object of study. In addition, three different quantitative indicators are selected to evaluate each sustainability 
dimension. The selection of metrics and indicators could be modified according to the system to be analyzed.

The case studies presented in this paper are the results of the implementation of the methodology presented above in higher education to develop bachelor's and master's degree final projects by design engineering students. The production stage of a cash management machine (product), the performance of a public nursery school (service), and the development of an itinerant exhibition (service) including preliminary conditioning works (product) were reviewed. Therefore, products and services of very different domains could be analyzed. In each case, a new design applying environmental, economic, and social sustainability strategies was projected, taking into account the fulfillment of initial design specifications.

A more sustainable design of a cash machine is already being developed by the manufacturing company, applying sustainability strategies that affect the design of some components. In the case of the daycare service, the implementation of a more flexible timetable as a design strategy is under study by the local institutions, since the local employment could be pushed up and the working routines facilitated. Finally, the design of a more sustainable itinerant exhibition using audiovisual equipment instead of a modular walls system is only in the project phase. In all cases, sustainability-oriented decision making can be carried out using the methodology proposed.

The introduction of sustainability assessment in bachelor's and master's degree final projects was very positively valued by the students, although it proved laborious because they lacked previous knowledge. The consciousness of the impacts their design decisions have on each of the analyzed dimensions was the most important aspect highlighted by the students.

Future research should expand the application of this approach to the sustainable design of complex systems composed of products and services, including a suitable identification of the links between the systems involved, and the study of the effects of strategic decisions on the sustainability of those systems. From the educational point of view, future work should focus on the implementation of sustainability assessment methods in regular courses as well, which will enable us to assess whether the students really submit more sustainable designs, and how their sustainability-related competencies have improved.

Author Contributions: Conceptualization, N.M.L., J.I.V.M., A.B., and J.L.S.S.; methodology, J.L.S.S.; validation, N.M.L. and A.B.; investigation, N.M.L., J.I.V.M., A.B., and J.L.S.S.; data curation, N.M.L., J.I.V.M., and A.B.; writing—original draft preparation, N.M.L., J.I.V.M., and J.L.S.S.; writing—review and editing, A.B. and A.F.-V.; visualization, N.M.L., J.I.V.M., and A.B., supervision, A.B.; All authors have read and agreed to the published version of the manuscript.

Funding: This research was funded by the University of Zaragoza, grant number UZ2020-TEC02: PLANTEAMIENTO DE UNA METODOLOGÍA DE DISEÑO SOSTENIBLE EN SISTEMAS PRODUCTO-SERVICIO.

Institutional Review Board Statement: Not applicable.

Informed Consent Statement: Not applicable.

Data Availability Statement: The additional data can be available on reasonable request.

Conflicts of Interest: The authors declare no conflict of interest. The funders had no role in the design of the study, in the collection, analyses, or interpretation of data, in the writing of the manuscript, or in the decision to publish the results.

\section{References}

1. Fiksel, J. Design for Environment: Creating Eco-Efficient Products and Processes; McGraw-Hill: New York, NY, USA, 1996.

2. Brezet, H. Ecodesign-A Promising Approach to Sustainable Production and Consumption; United Nations Environmental Programme (UNEP): Paris, France, 1997.

3. Wimmer, W.; Züst, R. ECODESIGN Pilot: Product Investigation, Learning and Optimization Tool for Sustainable Product Development with CD-ROM.; Springer Science \& Business Media: Berlin, Germany, 2003; Volume 3.

4. Bhamra, T.; Lofthouse, V. Design for Sustainability: A Practical Approach; Gower Publishing, Ltd: Aldershot, UK, 2007. 
5. Vezzoli, C.; Manzini, E. Design for Environmental Sustainability; Springer: London, UK, 2008.

6. ISO 14040 International Standard. In Environmental Management-Life Cycle Assessment-Principles and Framework; International Organisation: Geneva, Switzerland, 2006.

7. ISO, 2006b. ISO 14040 International Standard. In Environmental Management-Life Cycle Assessment-Requirements and Guidelines; International Organisation: Geneva, Switzerland, 2006.

8. Van Hemel, C.G. EcoDesign Empirically Explored: Design for Environment in Dutch Small and Medium-Sized Enterprises. Doctoral Thesis, Delft University of Technology, Delft, The Netherlands, 1998.

9. Andriankaja, H.; Vallet, F.; Le Duigou, J.; Eynard, B. A method to ecodesign structural parts in the transport sector based on product life cycle management. J. Clean. Prod. 2015, 94, 165-176. [CrossRef]

10. Vasantha, G.V.A.; Roy, R.; Lelah, A.; Brissaud, D. A review of product-service systems design methodologies. J. Eng. Des. 2012, 23, 635-659. [CrossRef]

11. WCED (World Commission on Environment and Development). Our Common Future; Oxford University Press: Oxford, UK, 1987.

12. UNCED, Agenda 21. In Proceedings of the United Nations Conference on Environment and Development, Rio de Janeiro, Brazil, 3-14 June 1992. Available online: https:/ / sustainabledevelopment.un.org/content/documents/Agenda21.pdf (accessed on 15 March 2021).

13. Klöpffer, W. Life cycle sustainability assessment of products. (with comments by Helias A. Udo de Haes, p. 95). Int. J. Life Cycle Assess. 2008, 13, 89-95. [CrossRef]

14. Finkbeiner, M.; Schau, E.M.; Lehmann, A.; Traverso, M. Towards life cycle sustainability assessment. Sustainability 2010, 2, 3309-3322. [CrossRef]

15. Valdivia, S.; Ugaya, C.M.; Hildenbrand, J.; Traverso, M.; Mazijn, B.; Sonnemann, G. A UNEP/SETAC approach towards a life cycle sustainability assessment-our contribution to Rio+ 20. Int. J. Life Cycle Assess. 2013, 18, 1673-1685. [CrossRef]

16. UNEP/SETAC. Guidelines for Social Life Cycle Assessment of Products; United Nations Environment Programme: Paris, France, 2009.

17. Ciroth, A.; Franze, J. LCA of an Ecolabeled Notebook: Consideration of Social and Environmental Impacts along the Entire Life Cycle; GreenDeltaTC GmbH: Berlin, Germany, 2011.

18. Steen, B.; Palander, S. A selection of safeguard subjects and state indicators for sustainability assessments. Int. J. Life Cycle Assess. 2016, 21, 861-874. [CrossRef]

19. Santolaya, J.L.; Lacasa, E.; Biedermann, A.; Muñoz, N. A practical methodology to project the design of more sustainable products in the production stage. Res. Eng. Des. 2019, 30, 539-558. [CrossRef]

20. Ren, J. Multi-criteria decision making for the prioritization of energy systems under uncertainties after life cycle sustainability assessment. Sustain. Prod. Consum. 2018, 16, 45-57. [CrossRef]

21. Maxwell, D.; Van der Vorst, R. Developing sustainable products and services. J. Clean. Prod. 2003, 11, 883-895. [CrossRef]

22. Maxwell, D.; Sheate, W.; Van Der Vorst, R. Functional and systems aspects of the sustainable product and service development approach for industry. J. Clean. Prod. 2006, 14, 1466-1479. [CrossRef]

23. Gagnon, B.; Leduc, R.; Savard, L. From a conventional to a sustainable engineering design process: Different shades of sustainability. J. Eng. Des. 2012, 23, 49-74. [CrossRef]

24. Pesonen, H.L.; Horn, S. Evaluating the Sustainability SWOT as a streamlined tool for life cycle sustainability assessment. Int. J. Life Cycle Assess. 2013, 18, 1780-1792. [CrossRef]

25. Ceschin, F. How the design of socio-technical experiments can enable radical changes for sustainability. Int. J. Des. 2014, 8, 1-21.

26. Vezzoli, C.; Kohtala, C.; Srinivasan, A.; Diehl, J.C.; Fusakul, S.M.; Xin, L.; Sateesh, D. Product-Service System Design for Sustainability; Greenleaf Publishing: Sheffield, UK, 2014.

27. Roozenburg, N.F.; Eekels, J. Product Design: Fundamentals and Methods; Wiley: Chichester, UK, 1995.

28. Pahl, G.; Beitz, W. Engineering Design: A Systematic Approach; Springer Science \& Business Media: Berlin, Germany, 1996.

29. Ceschin, F.; Gaziulusoy, I. Evolution of design for sustainability: From product design to design for system innovations and transitions. Des. Stud. 2016, 47, 118-163. [CrossRef]

30. Koo, Y. The role of designers in integrating societal value in the product and service development processes. Int. J. Des. 2016, 10, 49-65.

31. Wilson, G.T.; Bhamra, T.; Lilley, D. Evaluating feedback interventions: A design for sustainable behaviour case study. Int. J. Des. 2016, 10, 87-99.

32. Yoon, J.; Kim, C.; Kang, R. Positive user experience over product usage life cycle and the influence of demographic factors. Int. J. Des. 2020, 14, 85-102.

33. Tukker, A. Product services for a resource-efficient and circular economy-A review. J. Clean. Prod. 2015, 97, 76-91. [CrossRef]

34. Da Costa Fernandes, S.; Pigosso, D.C.; McAloone, T.C.; Rozenfeld, H. Towards product-service system oriented to circular economy: A systematic review of value proposition design approaches. J. Clean. Prod. 2020, 257, 120507. [CrossRef]

35. Muñoz Lopez, N.; Santolaya Saenz, J.L.; Biedermann, A.; Serrano Tierz, A. Sustainability Assessment of Product-Service Systems Using Flows between Systems Approach. Sustainability 2020, 12, 3415. [CrossRef]

36. European Parliamentary Research Services. The Ecodesign Directive; European Union: Brussels, Belgium, 2017; Available online: https:/ / www.europarl.europa.eu/RegData / etudes/STUD/2017/611015/EPRS_STU(2017)611015_EN.pdf (accessed on 3 June 2021). 
37. European Commission. Circular Economy Action Plan; European Union, Brussels 2020. Available online: https:/ / eur-lex.europa. eu/legal-content/EN/TXT/?qid=1583933814386\&uri=COM:2020:98:FIN (accessed on 3 June 2021).

38. Grierson, H.; Bohemia, E.; Buck, L. Proceedings of the 23rd International Conference on Engineering and Product Design Education (EEPDE 2021), VIA Design, Continuity and Adaptability in Design and Engineering Education, 9-10 September 2021; VIA University in Herning: Herning, Denmark, 2021; ISBN 978-1-912254-14-9.

39. Østergaard, T. The designer as agent of community. Proof of Concept: Service Design Conference; Linköping University Electronic Press: Linköping, Sweden, 2018.

40. Østergaard, T. Revising Creative Sustainability-competencies in Design Educations: The Future of Design. In Decoding European Creative Skills: The Future of Design; ELISAVA: Barcelona, Spain, 2019; pp. 13-19.

41. Leube, M.; Walcher, D. Designing for the next (Circular) Economy. An appeal to renew the Curricula of Design Schools. Des. J. 2017, 20, S492-S501.

42. Sumter, D.; de Koning, J.; Bakker, C.; Balkenende, R. Design competencies for a circular economy. In Proceedings of the PLATE Product Lifetimes and the Environment; Universitätsverlag der TU Berlin: Berlin, Germany, 2019; pp. 18-20.

43. Umweltbundesamt (UBA). German Environmental Protection Agency. 2007. Available online: https://www.probas. umweltbundesamt.de/php/index.php (accessed on 13 April 2017).

44. Mapama. Available online: http://www.miteco.gob.es/es/cambio-climatico/temas/mitigacion-politicas-y-medidas/factores_ emision_tcm30-446710.pdf (accessed on 16 April 2018).

45. BOA-106, Order August 25th of 2005; Education, Culture and Sport Department of Aragón. Available online: http:/ / www.boa.aragon.es/cgi-bin/EBOA/BRSCGI?CMD=VERDOC\&BASE=BZHT\&PIECE=BOLE\&DOCS=1-51\&DOCR= 3\&SEC $=$ FIRMA\&RNG=200\&SEPARADOR=\&SECC $-C=B O A \% 200 \% 20 D I S P O S I C I O N E S \% 200 \% 20 P E R S O N A L \% 200 \% 20$ ACUERDOS\%20O\%20JUSTICIA\%20O\%20ANUNCIOS\&PUBL-C=\&PUBL=20050905\&@PUBL-E= (accessed on 3 June 2021).

46. Millán, I.; Lacasa, E.; Sánchez, A.; Diago, L.; Santolaya, J.L. Methodology for a sustainable design of Product-Service Systems. In Advances on Mechanics, Design Engineering and Manufacturing II.; Springer: Cham, Switzerland, 2019; pp. 23-31. 